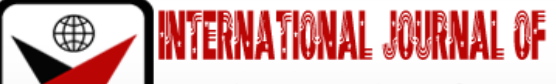

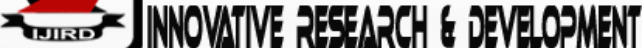

ISSN 2278-0211 (Online)

\section{Prevalence of Taenia Solium Taeniasis among Community Members of Kiambu County, Kenya}

\author{
Dr. Purity N. Nguhiu
Lecturer, Department of Animal Science, Kenyatta University, Kenya
Dr. Peterson Warutere
Lecturer, Department of Environmental and Occupational health, Kenyatta University, Kenya
David Mbuvi
Postgraduate Student, Department of Environmental and Occupational Health, Kenyatta University, Kenya
}

\section{Abstract:}

Taenia solium Taeniasis is an important zoonotic food borne intestinal parasitic disease causing abdominal pains, diarrhea and stunting in children. Humans get the infection on consumption of raw or under cooked infected pig meat with metacercode larvae or contaminated food and water. Adult worm is found in the intestines of humans, eggs are shed in feces constituting environmental contamination. Disease occurs worldwide but it is endemic where pigs are raised in free range system. A total of three hundred and eighty four stool samples were collected from 386 (163 males and 223 females) randomly selected adult members of the community members in Thika, Kiambu in 2016 for parasitological evaluation by microscopy for T. solium eggs. Each study participant signed an informed consent and provided one stool sample.

Twenty six of the participants both males and females were found to be positive for T. solium eggs indicating an overall prevalence of $6.74 \%$. Significant associations were observed in relation to latrine use $\left(X^{2}=43.406, p\right.$ value $\left.=0.000\right)$, method of pork preparation $\left(X^{2}=10.271, p\right.$ value $\left.=0.006\right)$, and frequency of deworming at $\left(X^{2} 18.275, p\right.$ value $\left.=0.000\right)$. Taenia solium taeniasis is present in the community and in relatively high prevalence.

Keywords: Intestinal parasite, pork tapeworm, fecal diagnosis

\section{Introduction}

Taenia solium Taeniasis is a parasitic disease caused by infection with Taenia solium, also referred as the pork tapeworm.This is an important zoonosis of major public health concern worldwide (Eshitera et al, 2012). The adult worm resides in the intestines of infected person. Pork tapeworm infections are associated with ingestion of undercooked or raw meat from infected pig with T. solium cysticerci (Allan and Craig, 2006). Other studies have reported pork tapeworm infection associated with open human defecation and consumption of the excreta by un-confined pigs (Phiri et al, 2003). Eggs disseminated from human carriers may lead to autoinfection, constitutes contamination of environment, food and water which result in human Cysticercosis (Ngowi et al, 2009). The eggs develop into larvae with appearance of cysts in body organs and tissues such as the eye, muscles and the central nervous system. Pigs acquire the infection by ingesting T. solium eggs from faeces of human carriers or contaminated fodder leading porcine cysticercosis (Dorny et al, 2005).

Globally, T. solium estimates stand between at about 40 million cases (Eckert et al, 2005). Taenia solium Taeniasis is often neglected especially in developing countries of Sub- Sahara Africa, Latin America, and Asian. This may be attributed to scarcity of epidemiological data in these countries hence the assumption that the disease is rare (Mutua et al, 2010). However, various studies done in sub-Saharan Africa as well as other parts of the world have reported the emergence of cases in countries such as Tanzania, Zambia and Kenya (Phiri et al, 2006). Prevalence of human Cysticercosis and associated risk factors has been less studied in most African countries.

Currently, the understanding of the status of T solium Taeniasis as a severe and new concern to environmental and public well-being of the population in Africa has been on the rise, although there is scarcity of data on human cases which may be attributed to lack of reporting procedures, inadequate form of disease surveillance and poor monitoring platforms in endemic areas. There is little data on prevalence T. solium Taeniasis in Kenya and therefore this study has contributed to bridge that gap.

\section{Materials and Methods}

A cross-sectional study design was used to collect the research data among community members from Thika SubCounty, Kiambu County. The study was done among the residents aged twenty years and above in their respective

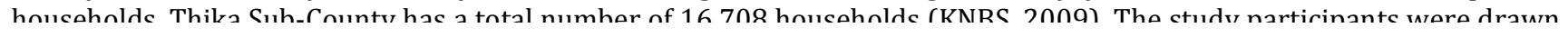


from the total number of the households. The sub County has five administrative wards and three of these namely Kamenu, Gatuanyaga and Township were selected randomly for this study. Households within the sampled clusters formed the sampling units. Systematic random sampling was used to select the household to participate for the study. Every $12^{\text {th }}$ household was included for the study. In cases where the household head declined to participate the next household was chosen. A total of 386 of study participants were recruited for this study comprising of 163 males and 223 females, 237 from Kamenu, 118 from Township and Gatuanyaga 29. Adults aged twenty years and above who were residents in the area for more than six months were recruited for this study.

A semi structured questionnaire was administered to gather demographic data of the study participants, information on availability and use of latrine facilities, preferred method of pork preparation, and frequency of deworming. A uniquely labeled stool sample collection tube that matched the details on the questionnaire was issued to each study participant at the end of the interview, and requested to provide a stool sample which was collected the following day.

A total of 386 stool samples were submitted to the Galaxy Medicare Consultants laboratory for parasitological evaluation for presence of Taenia solium eggs by microscopy as per standard procedure described in laboratory guidelines to determine the prevalence of T. solium Taeniasis (CDC, 2016).

Microscopic examination was done on direct wet film and iodine stained preparations. The slide smears were examined for ova and cysts of helminthes and protozoa with particular emphasis for Taenia eggs, scolexes or proglottids. Since Taenia spp eggs are identical, a follow up procedure was done to all positive Taenia spp samples for species determination through sieving the samples to find proglottids or scolexes which were microscopically observed. Species determination samples were prepared with lacto phenol (50/50 liquefied phenol crystals in lactic acid) and Indian ink injection was done for 30 minutes and sandwiched between two glass microscope slides. Indian ink was then injected into the pores and the number of primary uterine branches was counted to determine the species (7-13 for T. solium and 12-30 for T. saginata).

Qualitative pre coded data was entered into statistical program for social science (SPSS) software, version 20 for data analysis. The data operations was both analytical and descriptive. Proportions such as mean, median, frequency and range were used. For bivariate and multivariate analysis $\left(\chi^{2}\right)$ while Chi square was used for associations of prevalence to study variables.

The study was reviewed by the Kenyatta University Ethical and Review Committee and approved by the Ministry of Health, Kiambu County. Permission to carry out the research was sought from the National Commission for Science and Technology (NACOSTI). All study participants were recruited on voluntary basis, signed a written informed consent and were free to decline or withdraw from the study at any time during the interview.

Brief health education was given to all study participants as part of the engaging process and seeking consent. The life cycle of T.solium with emphasis on methods of transmission, disease in animals and humans as well as prevention of infection were explained. Simple diagrams and pictures were used to make the explanations more clear and public health and economic importance discussed. All individuals with positive cases of T. solium Taeniasis on microscopy were advised to seek medical care.

\section{Results}

The age range of study participants was 20 to 65 years with $50 \%$ in the 30 to 49 and $9.6 \%$ older than 60 years. On marital status, total of $76 \%$ had attained primary and secondary level education, $19 \%$ college level while the rest had no formal education. Ninety eight percent were Christians and 2\% were Adventists. Salaried people and business men accounted for $42 \%$ percent of the study respondents while the rest animal and crop husbandry farmers and casual laborers. Demographics of the respondents in relation to presence or absence of T. solium in the study participants and the statistical associations in the study of Taenia solium Taeniasis in Kiambu, Kenya in 2016 were as shown in Table 1.

On parasitological evaluation, a total of twenty six stool samples from the study participants with equal number of males and females recorded to be positive for T. solium eggs indicating an overall point prevalence of $6.74 \%$.

In relation to administrative Ward of the respondent, 15 out of 239 (6.3\%) examined in Kamenu 8 out of 118 $(6.74 \%)$ in Township and 3 out of $29(10.3 \%)$ in Gatuanyaga were positive for T. solium eggs. Prevalence was significantly associated with the Ward of the respondent at $\left(\chi^{2}=6.485, \mathrm{df}=2, \mathrm{P}\right.$ value $\left.=0.039\right)$.

The gender of the respondents was considered, 13 out of the 163 males (7.98\%) and 13 out of the 223 females $(5.83 \%)$ were positive for T. solium. However, there was no statistically significant difference in prevalence associated with the gender of the respondent at $\left(\chi^{2}=0.710, \mathrm{df}=1, \mathrm{P}\right.$ value $\left.=0.399\right)$.

Taenia solium Taeniasis infections occurred in all age groups, 20 years and above with no significant statistical significance in the distribution.

The data from the study questionnaires was analysed for various themes and trends in relation to presence of Taenia solium Taeniasis among the study participants. Among the participants who were positive for Taeniasis, majority $(85 \%)$ used or had access to latrines while $15 \%$ reported that they had no access. The use of latrines was significantly associated to occurrence of T. solium. All who were positive for T. solium were pork consumers, 77\% preferred roast pork and this method of pork preparation was significantly associated with the occurrence of T. solium. Majority (75\%) respondents reported that they took worm medication, however the frequency was rare and 8 among them were positive for T. solium. Fifteen among the positive cases reported that they had never dewormed themselves. Failure and low frequency of deworm were significantly associated with the presence of T. solium among the study participants.

Risk factors in relation to presence or absence of $\mathrm{T}$. solium in the study participants and the statistical associations in the study of Taenia solium Taeniasis in Kiambu, Kenya in 2016 were as shown in Table 2. 


\section{Discussion}

This study showed presence of Taenia solium Taeniasis among adult community members in Thika sub-County, Kiambu with a high prevalence of $6.74 \%$.

The estimated prevalence of Taenia solium taeniasis in sub Saharan Africa ranges from 2.4\% to $10.8 \%$. Specifically in Zambia the prevalence was reported at 6.3\% (Mwape et al, 2011), Burundi at 6.9\% (Mwanjali et al, 2013) and in Senegal was at 7.7\% estimated using microscopic examination of stool. In Uganda, Kisakye and Masada found prevalence at 9.4\% (Kisakye and Masaba, 2002), while in Ghana it was found at 13.5\% (Newell et al, 1997). The current study used microscopic examination of stools which is similar to the studies reported and the findings are consistent.

In Busia district of Kenya work done by Githigia and others (Githigia et al, 2002) reported a prevalence of 4-10\% on a review on Busia district hospital records which is consistent with the study findings in Kiambu County. However, community based studies on prevalence of Taenia solium Taenisis had not been reported before in the study area or elsewhere in Kenya. The current study reports on significant prevalence and risks that was associated with occurrence taeniasis.

Globally, World Health Organization in 2014 estimated the prevalence of Taeniasis by all tapeworm species to stand at 13.5\% (WHO, 2014). Garcia and other researchers in a study amongst rural populations in Peru found a prevalence of $6.2 \%$ (Garcia et al, 2003), while Gomes and others reported prevalence of 8.6 in Brazil (Gomes et al. 2007). These findings are consistent with the current study. These findings are not consistent with the current study and trends in sub Saharan Africa and low prevalence may be attributed to level of development and availability of sanitary facilities.

The use of more sensitive methods for diagnosis has reported higher prevalence. Study carried out in Democratic Republic of Congo and reported prevalence of $21.65 \%$ using Ag ELISA (Rodriguez et al, 1998). These findings from developing countries where the risk factors are not expected to be significantly different may be attributed to the fact that more sensitive and specific methods were used.

Studies in North Cameroon reported that $40 \%$ the households have no latrine facility and the pig owners use open field defaecation which may maintain transmission in the area (Assana et al, 2010). The method of pork preparation may pose risk for consumers with most of the pork meat consumers preferring roasting while studies suggest that cysticerci may not be completely destroyed in roast or fried pork (Mopate et al, 2005). Effective anthelminthics exist for control and treatment of taenisis but most adults do not take any medication to control any kind of worms.

This was the first community based study on prevalence of Taenia solium Taenisis had not been reported before in the study area or elsewhere in Kenya. Though this study was conducted in a peri- urban area where most of the homesteads had latrine facilities a significant percentage of those who were positive for T. solium taeniasis reported that they did not use latrines which may maintain transmission in the study area. Most of the pork meat consumers preferred roasting as method of preparation. A significant number of those who were positive reported that they never took any medication to control any kind of worms. The pig production system practiced in this area is mainly small holder intensive which is expected to reduce transmission of taeniasis yet the condition was present at prevalence.

The current study on overall Taenia solium prevalence only utilized microscopy based examination whose sensitivity and specificity are low hence prevalence is likely to be underestimated. Single stool sample per participant was also analysed hence intermittent proglottid shedding may not have been detected. The study did not include children.

\section{Conclusion}

The study concludes that Taenia solium Taeniasis is present among the community of Thika sub- County with high prevalence as reported globally. The prevalence was significantly associated to lack of latrine, method of pork preparation, and deworming practices of the participants. The study recommended that measures should be put in place to address the high T. solium Taeniasis prevalence in the area. It was further recommended further research using more sensitive and high specificity methods be used to determine the true prevalence of T. solium Taeniasis in Kiambu County.

\section{Acknowledgements}

The authors are grateful to the members of Thika community who participated in this study and the public health staff who assisted in data collection.

We extend our appreciation to the Kiambu County Government- Ministry of Health Services (Public Health) and Ministry of Agriculture and Livestock (Veterinary Service) are acknowledged for permission to carry out the work, support in data collection and Galaxy Medicare Consultants for Parasitological evaluation of the stool samples.

This work was supported by the Kenyatta University, Vice Chancellor's 2015/2016 Research Grant. 


\begin{tabular}{|c|c|c|c|c|c|}
\hline \multirow{2}{*}{$\begin{array}{c}\text { Demographic Factors } \\
\text { Respondents age } \\
\end{array}$} & \multicolumn{2}{|c|}{$\begin{array}{l}\text { Presence or Absence of } \mathrm{T} \text {. } \\
\text { Solium in the Sample }\end{array}$} & \multicolumn{3}{|c|}{ Statistical Association } \\
\hline & Positive & Negative & & & \\
\hline $20-29$ & $7(8.0 \%)$ & $81(92.0 \%)$ & & & \\
\hline $30-39$ & $4(3.4 \%)$ & $115(96.6 \%)$ & & & \\
\hline $40-49$ & $5(6.0 \%)$ & $79(94.0 \%)$ & & & \\
\hline $50-59$ & $7(12.7 \%)$ & $48(87.3 \%)$ & & & \\
\hline $60>$ & $3(7.5 \%)$ & $37(92.5 \%)$ & $\chi^{2}=5.627$ & $\mathrm{df}=4$ & $P$ value $=0.229$ \\
\hline \multicolumn{6}{|c|}{ Marital status of the respondents } \\
\hline Married & $17(5.70 \%)$ & $280(94.30 \%)$ & & & \\
\hline Single & $5(8.20 \%)$ & $56(91.80 \%)$ & & & \\
\hline Widower & $1(16.70 \%)$ & $5(83.30 \%)$ & $\chi^{2}=3.103$ & $\mathrm{df}=4$ & $\mathrm{P}$ value $=0.541$ \\
\hline \multicolumn{6}{|c|}{ Education level of the respondent } \\
\hline No formal education & $5(1.30 \%)$ & $11(2.80 \%)$ & & & \\
\hline Primary & $8(9.90 \%)$ & $73(90.10 \%)$ & & & \\
\hline Secondary & $7(4.80 \%)$ & $140(95.2 \%)$ & & & \\
\hline College & $3(5.30 \%)$ & $54(94.70 \%)$ & $\chi^{2}=21.089$ & $\mathrm{df}=6$ & $P$ value $=0.020^{*}$ \\
\hline \multicolumn{6}{|c|}{ Religion of the respondent } \\
\hline Christian & $23(6.10 \%)$ & $357(93.90 \%)$ & & & \\
\hline Adventist & $3(42.90 \%)$ & $4(57.10 \%)$ & $\chi^{2}=14.856$ & $\mathrm{df}=1$ & $P$ value $=0.000^{*}$ \\
\hline \multicolumn{6}{|c|}{ Occupation of the respondents } \\
\hline Salaried employment & $8(7.80 \%)$ & $95(92.20 \%)$ & & & \\
\hline Business & $4(6.70 \%)$ & $56(93.30 \%)$ & & & \\
\hline Casual labor & $7(13.20 \%)$ & $46(86.80 \%)$ & & & \\
\hline Animal husbandry & $7(5.40 \%)$ & $122(94.60 \%)$ & & & \\
\hline Crop farming & $0(0.00 \%)$ & $39(100.00 \%)$ & $\chi^{2}=7.111$ & $\mathrm{df}=5$ & $P$ value $=0.213$ \\
\hline
\end{tabular}

Table 1: Demographics of the Respondents in Relation to Presence or Absence of T. Solium in the Study Participants and the Statistical Associations in the Study of Taenia Solium

Taeniasis in Kiambu, Kenya In 2016

$X^{2}$-Chi Square Tests, Df- Degrees of Freedom, P Value $\leq 0.05$,

Values With [*] Were Significantly Associated

\begin{tabular}{|c|c|c|c|c|c|c|}
\hline Risk Factors & \multicolumn{2}{|c|}{$\begin{array}{l}\text { Presence or Absence of T. } \\
\text { Solium in Sample }\end{array}$} & \multicolumn{4}{|c|}{ Statistical Association } \\
\hline Latrine use & Positive & Negative & & & & \\
\hline Yes & $22(5.80 \%)$ & $360(94.20 \%)$ & & & & \\
\hline No & $4(80.00 \%)$ & $1(20.00 \%)$ & $\chi^{2}=43.406$ & $\mathrm{df}=1$ & $P$ value $=0.000^{*}$ & \\
\hline \multicolumn{7}{|l|}{ Pork consumption } \\
\hline Yes & $26(7.40 \%)$ & $326(92.60 \%)$ & & & & \\
\hline No & $0(0.00 \%)$ & $29(100.00 \%)$ & $\chi^{2}=2.29$ & $\mathrm{df}=1$ & $P$ value $=0.129$ & \\
\hline \multicolumn{7}{|c|}{ Preferred method of pork preparation } \\
\hline Roast & $20(11.60 \%)$ & $145(88.40 \%)$ & & & & \\
\hline Boil & $2(6.20 \%)$ & $30(93.80 \%)$ & & & & \\
\hline Fry & $4(2.50 \%)$ & $156(97.50 \%)$ & $\chi^{2}=10.271$ & $\mathrm{df}=2$ & $P$ value $=0.006^{*}$ & \\
\hline \multicolumn{7}{|c|}{ Respondent takes deworming medication } \\
\hline Yes & $8(2.80 \%)$ & $282(97.20 \%)$ & & & & \\
\hline No & $18(18.60)$ & $79(81.40 \%)$ & $\chi^{2}=28.947$ & $\mathrm{df}=1$ & $\mathrm{P}$ value $=0.000^{*}$ & \\
\hline \multicolumn{7}{|c|}{ Frequency of taking deworming medication } \\
\hline Rarely (once a year) & $4(3.30 \%)$ & $119(96.70 \%)$ & & & & \\
\hline $\begin{array}{l}\text { Occasionally (every six } \\
\text { months) }\end{array}$ & $6(4.30 \%)$ & $131(95.70 \%)$ & & & & \\
\hline $\begin{array}{c}\text { Often (every three } \\
\text { months) }\end{array}$ & $1(2.90 \%)$ & $34(97.10 \%)$ & & & & \\
\hline Never & $15(16.50 \%)$ & $76(83.50 \%)$ & $\chi^{2}=18.275$ & $\mathrm{df}=3$ & $\mathrm{P}$ value $=0.000^{*}$ & \\
\hline
\end{tabular}

Table 2: Risk Factors in Relation to Presence or Absence of T. Solium in the Study Participants and the Statistical Associations in the Study of Taenia Solium Taeniasis in Kiambu, Kenya in 2016

$X^{2}$-Chi Square Tests, Df- Degrees Of Freedom, P Value $\leq 0.05$, Values With [*] Are Significantly Associated 


\section{References}

i. Allan, J.C., and Craig, P.S. (2006). Detection, screening and community epidemiology of taeniicestodes zoonoses: cystic echinococosis, alveolar echinococosis and neurocysticercosis.Journ of Advan Parasitol, 38: 169- 250.

ii. Assana, E., Amadou, F., Thys, E., Lightowlers, M.W., Zoli, A.P., Dorny, P, Geerts. S. (2010). Pig farming systems and porcine cysticercosis in the North of Cameroon. J. Helminthol, 84: 441-6.

iii. Centers for Disease Control and Prevention. (2016). Resources for health professionals 1600

iv. Clifton Rd, Atlanta GA30329-4027, USA800-CDC-INFO (800-232-4636) TTY: (888):

v. 232-6348.

vi. Dorny, P., Phiri, I.K., Vercruysse, J., Gabriel, S., Willingham, A.L.. (2004). A Bayesian approach for estimating values for prevalence and diagnostic test characteristics of porcine Cysticercosis. Int J Parasitol, 34: 569-576.

vii. Eckert, J., Zinkomagel, R.M., Keyser, F.H., Bienz, K.A. (2005). Medical Microbiology.Stuttgart Thieme. pp. 560. ISBN 9781588902450

viii. Eshitera, E., Githigia, S.M., Kitala, P.M. et al. (2012). Prevalence of porcine cysticercosis and associated risk factors in free range pigs in Homa-Bay district, Kenya. BMC Vet Research,

ix. 8: 234 .

x. Garcia, H.H., Gonzalez, A.E., Evans, C. A.W., Gilman, R.H, and Cysticercosis Working Group.(2003). Taenia solium cysticercosis. Lancet, 362: 547-556. [PMC free article] [PubMed

xi. Githigia, S.M., Murekefu, K., Ngesa, S.M., Otieno, R.O., Kahai, R. (2002).The prevalence ofPorcine cysticercosis and risk factors in Funyula division of Busia District, Kenya. Proceedings of the 11th annual meeting of ENRECA livestock research project in Easternand Southern Africa, Lusaka, Zambia, pp 30-58.

xii. Gomes, A.B., Soares, K.A. et al. (2007). "Comparative evaluation of different immunoassays for the detection of Taenia solium cysticercosis in swine with low parasite load." Mem

xiii. Inst Oswaldo Criz Rio de Janeiro, 102(6): 725-731.

xiv. Kisakye, J.M. and Masaba, S.C. (2002). Cysticercus cellulose in pigs slaughtered in and around

xv. Kampala City. Uganda Journal of Agricultural Sciences, 7: 23-4.

xvi. KNBS. Kenya National Bureau of Statistics National Census Report (2009).

xvii. Mopate, L.Y., Koussou, M.O., Kabore-Zoungrana, C.Y. (2005). Consumers and consumption of pork outside homes in the city of N'Djaména (Tchad). In: Parrot L, Njoya A, Temple L, Assogba-Komlan F, Kahane R, Ba Diao M, Havard M. (Eds.), Agriculture and urban development in West and Central Africa, Proceedings of International Workshop. IRAD,INRAB, ISRA and CIRAD, 31 October-03 November 2005,Yaoundé, Cameroun, pp. 135-140

xviii. Mutua, F.K., Arimi, S., Ogara, W. and Schelling, E. (2010). Farmer perceptions onindigenous pig farming in Kakamega district, Western Kenya. Nordic J Afr Stud, 19: 43-57.

xix. Mwanjali, G., Kihamia, C., Kakoko, D.V. et al. (2013). Prevalence and risk factors associatedwith human Taenia solium infections in Mbozi district, Mbeya Region, Tanzania. PLoS Neg Trop Dis, 7: e2102. [PMC free article] [PubMed]

xx. Mwape, K.E., Praet, N., Benitez-Ortiz, W., Muma, J.B., Zulu, G. (2011). Field evaluation of urine antigen detection for diagnosis of Taenia solium cysticercosis. Trans R Soc Trop

xxi. Med Hyg, 105: 574-8.

xxii. Newell, E., Vyungimana, F., Geerts, S., Kerckhoven, I.V., Tsang, V.C.W., Engels D. (1997).

xxiii. Prevalence of cysticercosis in epileptics and members of their families in Burundi.

xxiv. Trans R Soc Trop Med Hy, 91: 389-391.Ngowi, H.A., Mlangwa, J.E.D., Mlozi, M.R.S. et al. (2009). Implementation and evaluation of a health-promotion strategy for control of Taenia solium infections in northern Tanzania. Int Health Promot Educ, 47: 24-34.

xxv. Phiri, I., Dorny, P., Gabriël, S. et al. (2006). Assessment of routine inspection methods for porcine cysticercosis in Zambian village pigs. J Helminthol, 80(1): 69-72.Phiri, I.K., Ngowi, H., Afonso, S. et al. (2003). The emergence of Taenia solium Cysticercosis in Eastern and Southern Africa as a serious agricultural problem andpublic health risk. Acta Trop, 87: 13-23.

xxvi. Rodriguez, C.R., Allan, J.C., Dominguez, J.L et al. (1998). Application of an immunoassay to determine risk factors associated with porcine cysticercosis in rural areas of Yucatan, Mexico. Vet Parasitol, 79: 165-180.

xxvii. WHO. (2014). Multi criteria-Based Ranking for Risk Management of Food-Borne Parasites.Microbiological Risk Assessment Series No.23.Food and Agriculture Organization of the United Nations/ World Health Organization, Rome 